\title{
The Effect of Blue-light-emitting Diodes on Antioxidant Properties and Resistance to Botrytis cinerea in Tomato
}

\author{
Kangmin Kim ${ }^{1 \#}$, Hee-Sun Kook ${ }^{1 \#}$, Ye-Jin Jang ${ }^{1}$, Wang-Hyu Lee ${ }^{2}$, Seralathan Kamala-Kannan ${ }^{1}$, Jong-Chan Chae ${ }^{1 *}$ and Kui-Jae Lee ${ }^{1 *}$
}

${ }^{1}$ Division of Biotechnology, Advanced Institute of Environment and Bioscience, Chonbuk National University, Iksan 570-752, Korea

${ }^{2}$ Department of Agricultural Biology, College of Agriculture and Life Sciences, Chonbuk National University, Jeonju 561-756, Korea

\#These authors contributed equally to this work

\begin{abstract}
In higher plants, blue-light is mainly perceived by cryptochromes and phototropins, which subsequently orchestrates phototropism, chloroplast relocation, stomatal opening, rapid inhibition of hypocotyl elongation and leaf expansion. Blue-light signaling is also known to mediate the plant responses to biotic stresses, but relevant mechanisms are largely unknown. Here, we demonstrated that blue LED (Light Emitting Diode)-driven inhibition of gray mold disease was highly correlated with the increases in cellular protectants like proline, antioxidants and ROS (Reactive Oxygen Species) scavenger activities. After twenty one days of exposure to various wavelengths of LED lights, blue-LED treated tomato displayed significant increases in proline accumulation in the leaves and stems, whereas red- and green-LED treated tomato exhibited the lower proline contents. Similarly, the blue-LED treatment increased the amount of polyphenolic compounds in tomatoes, compared to other wavelength of LED lights. The activities of various ROS (Reactive Oxygen Species) scavenging enzymes were also slightly increased under the blue-LED lighted conditions. Finally, blue-LED significantly suppressed symptom development of tomato infected by gray mold. Combined results suggest that blue LED light inhibits the development of gray mold disease, which can be mechanistically explained by the enhanced proline accumulation and antioxidative processes at least in partial.
\end{abstract}

Keywords: Tomato; LED (Light Emitting Diode); Antioxidative defense system; Botrytis cinerea, Blue light

\section{Introduction}

Tomato (Lycopersicon esculentum Mill.) is the one of major greenhouse vegetable crops throughout the world. In terms of nutritional value, tomato is an excellent source of vitamin $\mathrm{A}$ and $\mathrm{C}$, carotenoids, $\alpha$-tocopherol, as well as phenolic compounds as antioxidants [1]. However, the quantity or quality levels of such phytochemicals vary considerably depending on genotype, and/or environmental conditions [2]. In greenhouse environment, phytopathogenic attack leads to retarded growth, damages to cell viability and eventually reduction of plant productivity $[3,4]$. In particular, the gray mold is the most widespread fungal disease in plants and caused by Botrytis cinerea, a necrotrophic fungal pathogen attacking fruits, vegetables and flowers of horticultural crops [3]. This fungus has great adaptability under broad environmental conditions, and is well known to rapidly develop fungicide resistance lines [5]. In horticultural aspects, optimization of cultivation conditions, such as temperature, humidity and light regimes might mitigate disease via modulating metabolite levels, and/or cellular compositions.

Light critically regulates the plant growth by regulating the various morphological and physiological changes of grown plants [6,7]. Recently, light-emitting diode (LED) as artificial light source for plant growing in controlled-environment have a variety of advantages, such as small volume, durability, longevity and selectable narrow-waveband emissions [8]. A few studies using this technology have been carried out on the effect of the light spectral quality on the plant growth and morphogenesis, as well as physiological responses by photooxidative changes $[7,9,10]$. It has been reported that red light, mainly perceived by Phytochromes (Pyr), is important for shoot growth including stem elongation on strawberries [11]. Wang et al. [12] found that disease resistance to Sphaerotheca fuliginea in cucumber plants was induced by red light. On the other hand, blue lights are perceived by majorly two different receptor family, cryptochromes and phototropins. The activation of blue light signaling modulates the various physiological and developmental processes, such as phototropism, chloroplast relocation, stomatal opening, rapid inhibition of hypocotyl elongation and leaf expansion [13]. It is known that blue light also regulates the responses against biotic environmental stresses. Arabidopsis CRY1 (Cryptochrome1) positively regulated resistance to Pseudomonas syringae, potentially via effector-triggered $\mathrm{R}$ protein-mediated local resistance [14]. In addition, stability of some $\mathrm{R}$ proteins is modulated by blue light receptors $[15,16]$. Nevertheless, the mechanistic basis underlying such blue light-driven protection is largely unknown.

In general, the oxidative burst involving generation of reactive oxygen species (ROS) is the earliest cellular responses, following recognition of a variety of bacterial and fungal pathogens [17]. The enhanced production of ROS is pre-requisite for hypersensitive response (HR) related to programmed cell death in systemic acquired resistance (SAR), but also damage to the major cellular components, such as DNA, lipids and proteins [18]. In a systemic tissues, in order to minimize oxidative stress by excess ROS, plants have developed detoxifying mechanisms consisting of antioxidants and some ROS scavenging enzymes, such as peroxidase, superoxide dismutase (SOD), catalase (CAT), ascorbate peroxidase (APX) [18]. Besides acting as an osmoprotectant, proline

*Corresponding authors: Kui-Jae Lee, Division of Biotechnology, Advanced Institute of Environment and Bioscience, Chonbuk National University, Iksan 570-752, Republic of Korea, Korea, Tel: +82-63-850-0836; Fax: +82-63-850 0834; E-mail: leekj@jbnu.ac.kr

Jong-Chan Chae, Division of Biotechnology, Advanced Institute of Environment and Bioscience, Chonbuk National University, Iksan 570-752, Korea, E-mail: chae@jbnu.ac.kr

Received August 27, 2013; Accepted September 24, 2013; Published September 30, 2013

Citation: Kim K, Kook H, Jang J, L ee W, Kamala-Kannan S, et al. (2013) The Effect of Blue-light-emitting Diodes on Antioxidant Properties and Resistance to Botrytis cinerea in Tomato. J Plant Pathol Microb 4: 203. doi:10.4172/21577471.1000203

Copyright: (c) $2013 \mathrm{Kim} \mathrm{K}$, et al. This is an open-access article distributed under the terms of the Creative Commons Attribution License, which permits unrestricted use, distribution, and reproduction in any medium, provided the original author and source are credited. 
also plays antioxidative roles by bringing concentrations of ROS within compatible ranges under the stressed conditions [19]. On the other hand, certain wavelengths of lights have been reported to increase antioxidative actions against abiotic challenges. In broad bean leaves, for instance, significantly increase of catalase activity under red light contributed to scavenging of hydrogen peroxide generated by Botrytis cinerea infection [20]. In addition, enhanced activities of CAT, as well as increased contents of total polyphenol and proline were observed in flax resistant to powdery mildew [21]. Regardless of these reports, the effects of light quality on the antioxidative status of plants are still largely open questions.

Here, we examined the roles of white-, blue-, red- and green-LED into the growth of tomato and analyzed the contents of proline, total phenol and the activities of antioxidant enzymes. Moreover, to shed light on the correlation between increased antioxdative capacity driven by LED lights and resistance to pathogenic attacks, we monitored the disease development of tomato under blue-LED lights.

\section{Materials and Methods}

\section{Plant growth conditions}

Tomato (cv. Toy-mini tomato) seeds were surface-sterilized in $70 \%$ ethanol for $5 \mathrm{~min}$ and in $2 \%$ sodium hypochlorite for $20 \mathrm{~min}$, followed by several rounds of washing with sterile water. Seeds were transferred to two sheets of sterile filter paper moistened with deionized water, and then germinated at $25^{\circ} \mathrm{C}$ under dark condition for three days. The uniformly germinated seedlings were transplanted into plastic culture tray $(25 \times 50 \times 5 \mathrm{~cm}$, the outer size of tray) containing peat-vermiculite media (Uddeumi, Sunghwa Co., Korea), and were grown for two weeks. For nutrition supply, the half-strength Hoagland solution [22] was irrigated. Growth chamber was set as the photoperiod of $18 \mathrm{hr}$ and 22 $\pm 1^{\circ} \mathrm{C}$ under a relative humidity $60-65 \%$ with a photon flux density of $150 \mu \mathrm{mol} / \mathrm{m}^{2} \mathrm{~s}$. The $\mathrm{pH}$ of nutrient solution was maintained at 5.8. At two weeks after transplanting, the tomato seedlings were planted into plastic pots $\left(10 \times 9 \mathrm{~cm}^{2}\right)$, at a density of one plant per pot and grown in phytotron chamber $(130 \times 60 \times 180 \mathrm{~cm}$, Woniltech, Ltd., Korea), for twenty one days under different light-emitting diode (LED) conditions. After morphological measurements, the leaves and stems tissues of tomato were ground to fine powder in liquid nitrogen for biochemical analyses.

\section{Light treatment conditions}

Each lighting treatment was conducted in separately controlled chambers (ODTech, Ltd., Korea), to be free from spectral interference among treatments. The LED array chambers were programmed to provide an $18 \mathrm{~h}$ light $/ 6 \mathrm{~h}$ dark photoperiod at photosynthetic photon flux (PPF) maintained of approximately $150 \mu \mathrm{mol} / \mathrm{m}^{2} \mathrm{~s}$. All tomato plants were grown under four different light sources with broadspectrum-white LED (BSWL, 420-680 nm) as a control, blue LED (460 $\mathrm{nm})$, red LED $(635 \mathrm{~nm})$ and green LED $(520 \mathrm{~nm})$. Light quality and quantity were estimated using a Testo545 light meter (Testo, Germany).

\section{Determination of proline content}

Determination of free proline content was performed as previously described [23]. Tomato leaf and stem samples $(0.5 \mathrm{~g})$ were homogenized in $3 \%(\mathrm{w} / \mathrm{v})$ sulfosalicylic acid and filtered through filer paper. Filtrate (2 $\mathrm{mL}$ ) was reacted with acid ninhydrin $(2 \mathrm{~mL})$ and $30 \%$ glacial acetic acid $(2 \mathrm{~mL})$, and then heated at $100^{\circ} \mathrm{C}$ for $1 \mathrm{~h}$. The reaction was extracted with $4 \mathrm{~mL}$ toluene for $30 \mathrm{~min}$ at room temperature; and the absorbance of the toluene fraction aspired from the liquid phase was measured at
$520 \mathrm{~nm}$. The proline concentration was determined based on a standard curve drawn with pure proline and expressed as $\mu \mathrm{mol}$ proline $\mathrm{g}^{-1} \mathrm{FW}$.

\section{Determination of total phenolic compounds}

The amount of total phenolics was determined using the FolinCiocalteu method [24]. Tomato leaf and stem samples $(0.5 \mathrm{~g})$ from each LED treatment were stirred slightly in $10 \mathrm{~mL}$ of $80 \%$ aqueous methanol. The suspension was sonicated for $5 \mathrm{~min}$ and collected by centrifugation. Samples $(500 \mu \mathrm{L})$ were reacted with Folin-Ciocalteu's reagent $(2.5 \mathrm{~mL})$ and $7.5 \%$ sodium carbonate $(2 \mathrm{~mL})$ at room temperature for $30 \mathrm{~min}$. The absorbance of the reaction product was measured at $765 \mathrm{~nm}$. The total phenolic concentration was determined using gallic acid as a standard, and expressed as gallic acid equivalents in milligrams per gram of dry matter

\section{Antioxidant enzyme analysis}

The activities of SOD, CAT, APX and GR were determined spectrophotometrically. SOD activity was assayed at $560 \mathrm{~nm}$ by determining the inhibition rate of nitroblue tetrazolium reduction, with xanthine oxidase as a hydrogen peroxide generating agent $[25,26]$. CAT activity was assayed at $240 \mathrm{~nm}$ by measuring the conversion rate of hydrogen peroxide to water and oxygen molecules [27]. APX activity was determined at $290 \mathrm{~nm}$ following the oxidation of ascorbate to dehydroascorbate, as described by Nakano and Asada [28]. GR activity was determined at $340 \mathrm{~nm}$ by measuring the reduction kinetics of oxidized glutathione [29].

\section{Detached leaf assay}

Botrytis cinerea (No. 40574) was obtained from the Korean Agricultural Culture Collection (KACC; Suwon, Korea). B. cinerea were incubated on potato dextrose agar (PDA) medium (MB Cell, Los Angeles, USA) containing $4 \%$ potato starch, $20 \%$ dextrose and $15 \%$ agar at $24^{\circ} \mathrm{C}$ in the dark. After two weeks, spores on the medium were suspended with sterilized distilled water (DW). Spore concentrations were adjusted to the approximately $5.7 \times 10^{5} \mathrm{~mL}^{-1}$ using a hemocytometer. If not otherwise stated, the spore suspension was used at the same concentration throughout the experiments. Detached leaves from 4-week-old tomato plants were washed with DW and placed on wet filter paper in Petri dishes. The leaves were inoculated with $10 \mu \mathrm{L}$ drops of the $B$. cinerea spore suspension $\left(5.7 \times 10^{5} \mathrm{~mL}^{-1}\right)$, and then kept under blue or broad-spectrum-white LED light conditions for 10 days. Disease severity on leaves infected with $B$. cinerea was visibly assessed on a scale of 0 ('no symptoms') to 4 ('51 to $100 \%$ symptoms'), according to the method of Rajkumar et al. [30].

\section{Statistical analysis}

Data were analyzed by a general linear model and multiple comparisons among the treatments were conducted by Tukey's honestly significant difference (HSD), using the statistical analysis program, Statistix (Statistix 9 Analytical Software, USA). The significance of differences among samples was determined at $95 \%$ confidence level.

\section{Results and Discussion}

In many plant species, proline is a major organic osmolyte that maintains osmotic balances, induces expression of stress responsive genes and functions to stabilize sub-cellular structures, scavenges free radicals and buffers cellular redox potential under stress conditions [31]. To explore the effect of different wavelength of light on the accumulation of proline, we quantitated the amount of proline in leaves and stem of tomato grown under LED light having different wavelengths. There was 
Citation: Kim K, Kook H, Jang J, L ee W, Kamala-Kannan S, et al. (2013) The Effect of Blue-light-emitting Diodes on Antioxidant Properties and Resistance to Botrytis cinerea in Tomato. J Plant Pathol Microb 4: 203. doi:10.4172/2157-7471.1000203

A

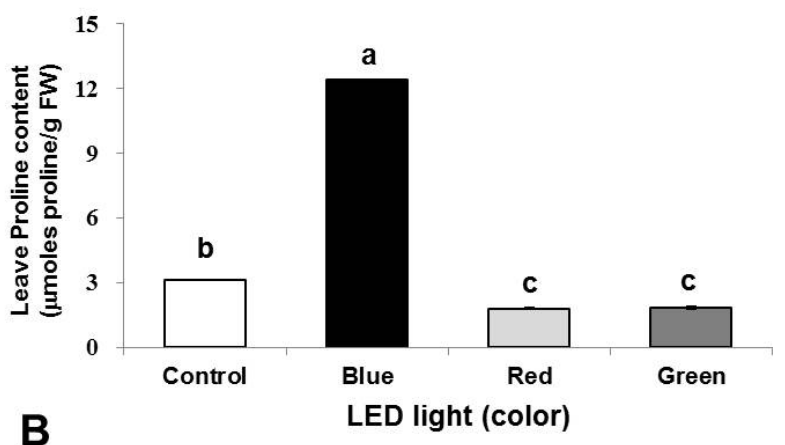

B

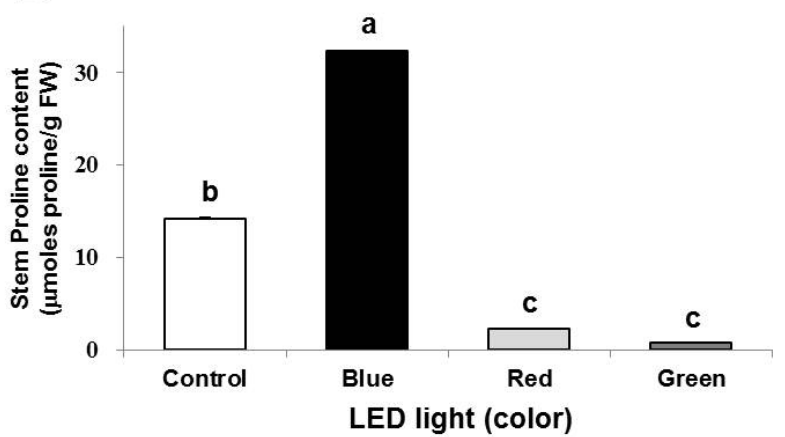

Figure 1: The content of proline in the leaves and stems of tomato grown for 21 days under light-emitting diode (LED) lights. Control represents broadspectrum-white LED. Error bars represents the standard deviation $(n=3)$. Bars with the same low case letter are not significantly different $(p>0.05)$, as assessed by Tukey's honestly significant difference.

a considerable difference in the content of proline of tomato seedlings lightened with different LED sources. Compared to broad-spectrumwhite LED (BSWL), when tomato seedlings were treated with blue-LED, proline contents were increased in leaves and stems by about $296 \%$ and $127 \%$, respectively. Each differences were statistically significant based on Tukey's HSD test with $\alpha=0.05(p<0.05)$. In contrast, red and green LED lights significantly decreased the amount of accumulated proline $(p<0.05$, Figure 1), compared to BSWL emitted conditions.

We also investigated the antioxidant capacity of tomato leaves and stems cultivated under different LEDs. In plants, antioxidant defense systems include various antioxidants, such as carotenoids, tocopherol, flavonoids, ascorbate and phenolic compounds, which play important roles in protection from photooxidative damage [11,21]. To learn how different wavelengths of light modulate antioxidation capacity in partial, we measured the contents of phenolic compounds from tomato grown under different colored LED lights. When blue LED was engaged, the content of total phenolic compounds both in leaves (1.3 fold) and stems (1.2 fold) was significantly increased (Tukey's test with $\alpha=0.05, p<0.05$ ), compared to BSWL conditions (Figure 2). On the other hand, under red and green light conditions, the content of total phenolic compounds of leaves showed a similar levels (Tukey's test with $\alpha=0.05)$ to BSWL conditions. However, in stems, red and green LED significantly decreased the contents of phenolic compounds by $49 \%$ and $37 \%$, respectively, compared to BSWL LED. Luthria et al. [32] reported that the quantity and composition of phenolic compounds in plants bearing edible fruits is significantly influenced by the quality of light. Furthermore, Johkan et al. [33] reported that the content of phenolic compounds was increased in red leaf lettuce, as a result of supplemental blue light radiation [33]. Our results are in agreement with data published by Johkan et al. [33], in which the content of polyphenols and antioxidant activity were shown to be greatly increased in lettuce seedlings treated with blue LED light. Taken together, our results clearly indicated that the contents of proline and total phenolic compounds in leaves and stems of tomato plants was considerably influenced by the spectral quality of LEDs. Especially, blue-LED dramatically increased the contents of proline and phenolic compounds in vegetative tissues in plants.

We also assessed the activity of antioxidant enzymes (e.g. SOD, CAT, APX, and GR) of tomato grown under each LED lights (Figure 3). In our study, no significant differences (Tukey's HSD test with $\alpha=0.05$ ) between the BSWL, blue, red and green light treatments were found for SOD activity in tomato leaves. However, in the case of stem, SOD activity was significantly increased by $29 \%$ under blue-LED treatment, while SOD activities under the red- and green-LED treated stems were decreased by $16 \%$ and $35 \%$, respectively, compared to BSWL LED treatment as a control (Tukey's HSD test with $\alpha=0.05$, Figure $3 \mathrm{~A}$ and $3 \mathrm{~B})$. Under the red- and green-LED treatment, however, CAT activity in leaves and stems were noticeably decreased by about $28 \%$ to $18 \%$ and $63 \%$ to $39 \%$, respectively, compared to BSWL LED light (Tukey's HSD test with $\alpha=0.05$, Figure 3C and 3D). In contrast, CAT activity in blue LED-treated tomato was increased about $15 \%$ in leaves compared to that in BSWL LED light treatment (Tukey's HSD test with $\alpha=0.05$ ). Being similar to our results, Schmidt et al. [34] reported that the activation of catalase enzyme in winter rye leaves was more enhances by blue light

A
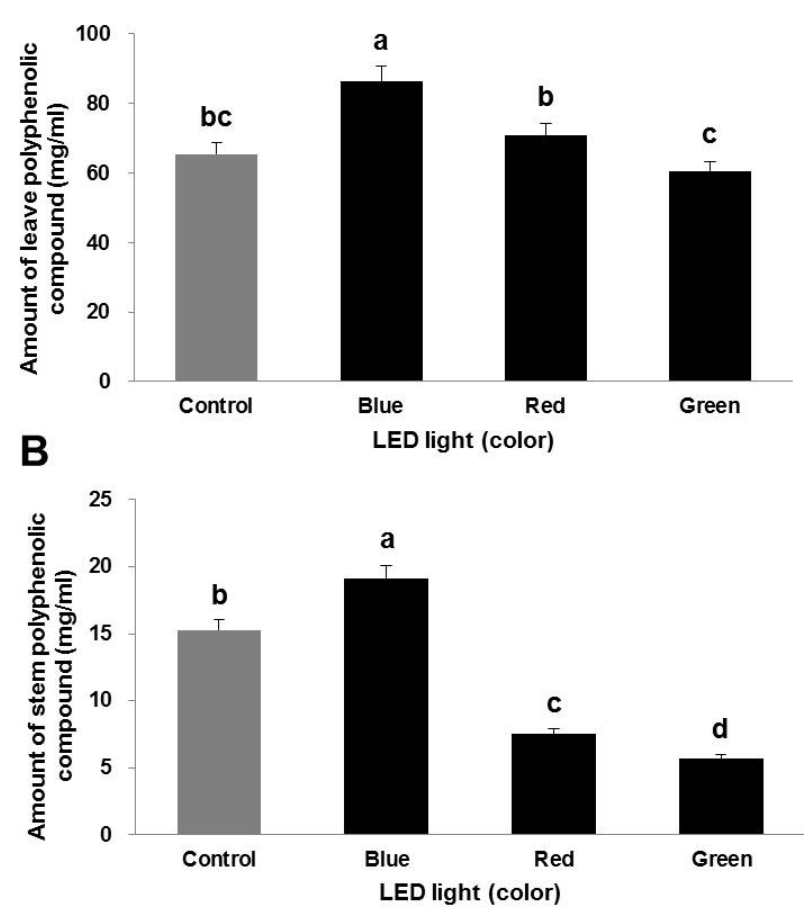

Figure 2: The content of total polyphenolic compounds in the leaves and stems of tomato grown for 21 days under light-emitting diode (LED) lights. Control represents broad-spectrum-white LED. Error bars represents the standard deviation $(n=3)$. Bars with the same low case letter are not significantly different $(p>0.05)$, as assessed by Tukey's honestly significant difference. 
Citation: Kim K, Kook H, Jang J, L ee W, Kamala-Kannan S, et al. (2013) The Effect of Blue-light-emitting Diodes on Antioxidant Properties and Resistance to Botrytis cinerea in Tomato. J Plant Pathol Microb 4: 203. doi:10.4172/2157-7471.1000203
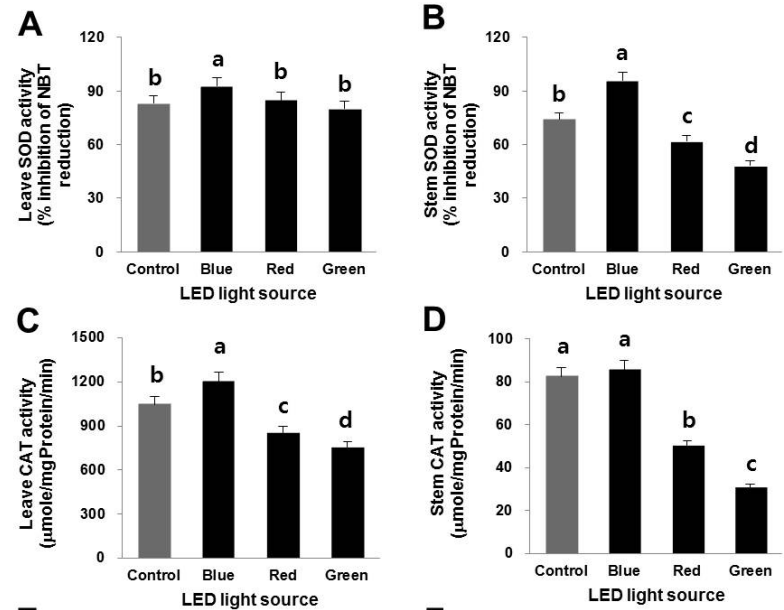

E

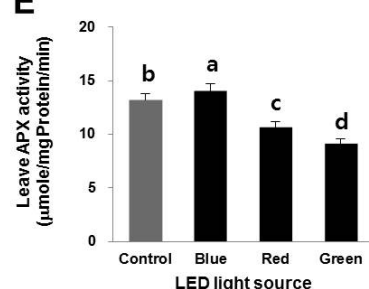

D

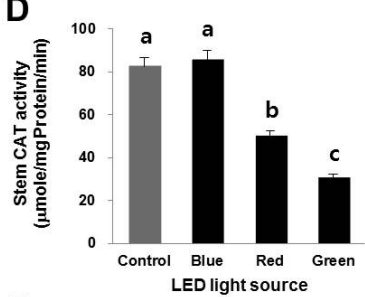

$\mathbf{F}$
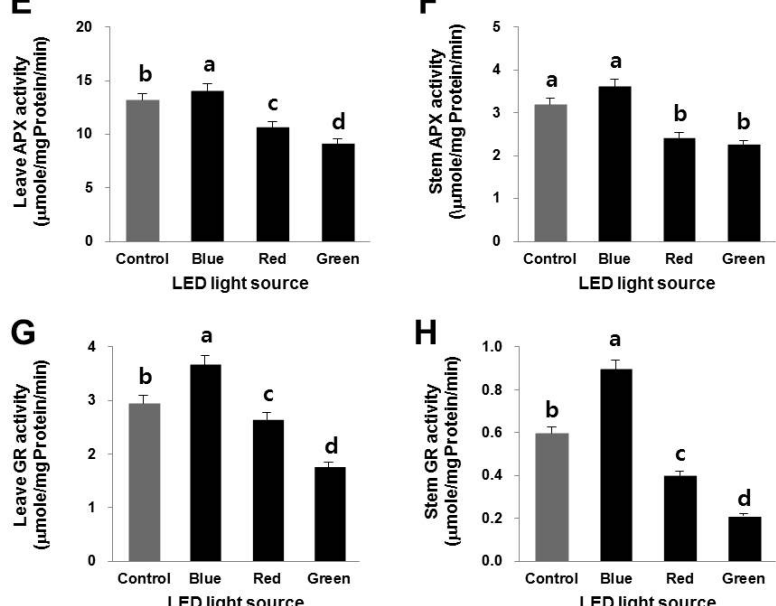

Figure 3: The activities of antioxidant enzymes in the leaves and stems of tomato grown for 21 days under light-emitting diode (LED) lights. (A,B) superoxide dismutase (SOD); (C,D) catalase (CAT); (E,F) ascorbate peroxidase (APX); and $(\mathrm{G}, \mathrm{H})$ glutathione reductase $(\mathrm{GR})$. Control represents broad-spectrum-white LED. Error bars represents the standard deviation $(n=3)$. Bars with the same low case letter are not significantly different $(p>0.05)$, as assessed by Tukey's honestly significant difference.

treatment than that in red or far-red light treatment. APX activity in blue-LED light treatment was also increased in leaves and stems by $7 \%$ and $13 \%$, respectively, compared to that in BSWL LED light treatment (Tukey's HSD test with $\alpha=0.05$, Figures $3 \mathrm{E}$ and $3 \mathrm{~F}$ ). In addition, in the case of GR activity of leaves and stems, the blue-LED treatment increased 1.4-fold and 2.1-folds (in leaves), 2.2-fold and 4.2-fold (in stems), compared to BSWL LED control (Tukey's HSD test with $\alpha=0.05$, Figure $3 \mathrm{G}$ and $3 \mathrm{H}$ ). In the leaves of tall fescue, $\mathrm{Xu}$ et al. [35] found that the activities of catalase (CAT), ascorbate peroxidase (APX) and glutathione reductase (GR) are increased by light treatment. Combined together, results of the present study indicated that blue-containing LED radiation had positive effects on the action of antioxidant defense mechanisms in tomato seedlings.

Inferred from the outstanding effects of blue-LED on proline contents and antioxidation capacities, we examined whether blueLED light treatment increased defense ability of tomato to gray mold disease caused by $B$. cinerea. Under the blue-LED light- and BSWLtreated tomato leaves, disease incidence of gray mold was 0.67 and

3.33, respectively. Such differences are statistically significant based on (Tukey's HSD test with $\alpha=0.05$, Figures $4 \mathrm{~A}$ and $4 \mathrm{~B}$ ). In tomato leaves, Kuzniak and Sklodowska [36] found that activity increases of peroxisomal antioxidant enzymes, such as superoxide dismutase (SOD), catalase (CAT) and glutathione peroxidase (GSH-Px) can contribute to the inhibition of pathogen-induced leaf senescence by Botrytis cinerea infection. Khanam et al. [37] reported that enhanced catalase activity under red light treatment contributes to the inhibition of lesion formation and fungal development on broad bean leaves infected with Botrytis cinerea. In addition, Grote and Claussen [38] reported that the proline content in tomato leaves is increased by pathogen attack such as phytophthora nicotianae, as well as light intensity. Thus, numerous studies have suggested that physiological resistance of plants to environmental stresses, including pathogen attack, is closely connected with specific light treatments, as well as effective antioxidative mechanisms. Similarly, our results suggest that blue-LED light suppress the development of gray mold, and/or the propagation of B. cinerea in tomato potentially via enhanced accumulation of proline and antioxidative responses.

In conclusion, current study suggests that blue-LED is highly efficient to protect crop plants from pathogenic attacks, at least where artificial lights are applied as main light sources. In mechanistic level, such advantages of blue-LED are ascribed into the increased production

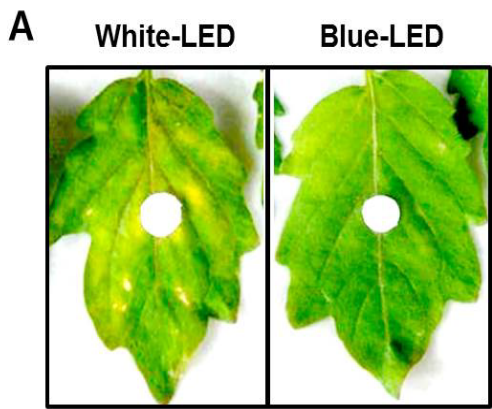

B

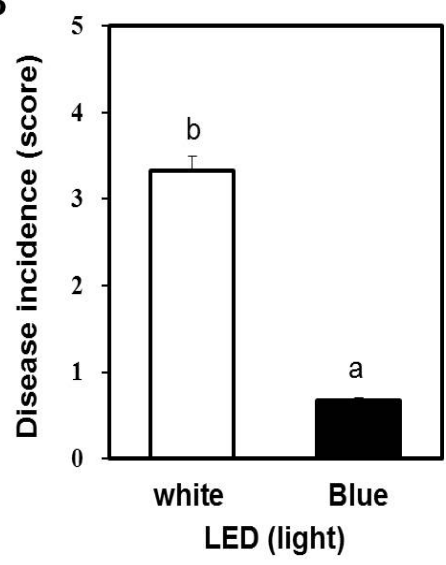

Figure 4: The effect of blue LED light on the resistance of tomato to B. cinerea. (A) Development of brown lesion in 4-week-old tomato seedlings infected by $B$. cinerea. Tomato leaves were inoculated with $B$. cinerea spores and then kept under broad-spectrum-white LED (control) and blue LED lights for 10 days. (B) Incidence of disease (mean \pm SD) was quantitatively assessed by the following indices: 0: no symptoms, 1 : $1-12 \%$ lesion, $2: 13-25 \%, 3: 26-50 \%$, and $4: 51-$ $100 \%$. Error bars represents the standard deviation $(n=3)$. Bars with the same low case letter are not significantly different $(p>0.05)$, as assessed by Tukey's honestly significant difference. 
Citation: Kim K, Kook H, Jang J, L ee W, Kamala-Kannan S, et al. (2013) The Effect of Blue-light-emitting Diodes on Antioxidant Properties and Resistance to Botrytis cinerea in Tomato. J Plant Pathol Microb 4: 203. doi:10.4172/2157-7471.1000203

of osmoprotectants and antioxidants, including ROS scavenging enzymes. Nevertheless, it must be prompted which signaling pathway are activated by blue light to gain more insight into the light wavelengthdependent developmental modifications in plants.

\section{Acknowledgment}

This research was supported by the National Research Foundation of Korea (NRF) grant funded by the government (MEST) (No.2011-0020202), and a grant (PJ007408) from the Rural Development Administration (RDA)

\section{References}

1. Fanasca S, Colla G, Maiani G, Venneria E, Rouphael Y, et al. (2006) Changes in antioxidant content of tomato fruits in response to cultivar and nutrient solution composition. J Agric Food Chem 54: 4319-4325.

2. Gahler S, Otto K, Bohm V (2003) Alterations of vitamin C, total phenolics, and antioxidant capacity as affected by processing tomatoes to different products. J Agric Food Chem 51: 7962-7968.

3. Williamson B, Tudzynski B, Tudzynski P, Van Kan JAL (2007) Botrytis cinerea the cause of grey mould disease. Mol Plant Pathol 8: 561-580.

4. Robert-Seilaniantz A, Navarro L, Bari R, Jones JD (2007) Pathological hormone imbalances. Curr Opin Plant Biol 10: 372-379.

5. Kretschmer M, Hahn M (2008) Fungicide resistance and genetic diversity of Botrytis cinerea isolates from a vineyard in Germany. J Plant Dis Protect 115 214-219.

6. Drozdova IS, Bondar VV, Bukhov NG, Kotov AA, Kotova LM, et al. (2001) Effects of light spectral quality on morphogenesis and source-sink relations in radish plants. Russ J Plant Physl 48: 415-420.

7. Li Q, Kubota C (2009) Effects of supplemental light quality on growth and phytochemicals of baby leaf lettuce. Environ Exp Bot 67: 59-64.

8. Massa GD, Kim HH, Wheeler RM, Mitchell CA (2008) Plant productivity in response to LED lighting. HortScience 43: 1951-1956.

9. Yorio NC, Goins GD, Kagie HR, Wheeler RM, Sager JC (2001) Improving spinach, radish, and lettuce growth under red light-emitting diodes (LEDs) with blue light supplementation. Hort Sci 36: 380-383.

10. Urbonaviciute A, Samuoliene G, Brazaityte A, Duchovskis P, Ruzgas V, et al. (2009) The effect of variety and lighting quality on wheatgrass antioxidant properties. Zemdirbyste 96: 119-128.

11. Samuoliene G, Brazaityte A, Urbonaviciute A, Sabajeviene G, Duchovskis $P$ (2010) The effect of red and blue light component on the growth and development of frigo strawberries. Zemdirbyste 97: 99-104.

12. Wang H, Jiang YP, Yu HJ, Xia XJ, Shi K, et al. (2010) Light quality affects incidence of powdery mildew, expression of defence-related genes and associated metabolism in cucumber plants. Eur J Plant Pathol 127: 125-135.

13. Shimazaki KI, Doi M, Assmann SM, Kinoshita T (2007) Light regulation of stomatal movement. Annu Rev Plant Biol 58: 219-247.

14. Xu Y, Sun X, Jin J, Zhou H (2010) Protective effect of nitric oxide on lightinduced oxidative damage in leaves of tall fescue. J Plant Physiol 167: 512-518.

15. Jeong RD, Chandra-Shekara AC, Barman SR, Navarre D, Klessig DF, et al. (2010) Cryptochrome 1 and phototropin 2 regulate resistance protein-mediated viral defense by negatively regulating an E3 ubiquitin ligase. Proc Natl Acad Sci U S A 107: 13583-13543.

16. Jeong RD, Chandra-Shekara AC, Barman SR, Navarre D, Klessig DF, et al (2010) Cryptochrome 1 and phototropin 2 regulate resistance protein-mediated viral defense by negatively regulating an E3 ubiquitin ligase. Proc Natl Acad Sci U S A 107: 13583-13543.

17. Torres MA, Jones JDG, Dangl JL (2006) Reactive oxygen species signaling in response to pathogens. Plant Physiol 141: 373-378.

18. Sharma P, Jha AB, Dubey RS, Pessarakli M (2012) Reactive oxygen species oxidative damage, and antioxidative defense mechanism in plants under stressful conditions. J Bot 2012: 1-26.

19. Hayat S, Hayat Q, Alyemeni MN, Wani AS, Pichtel J, et al. (2012) Role of proline under changing environments: A review. Plant Signal Behav 7: 1456-1466.

20. Islam SZ, Rahman MZ, Khanam NN, Ueno M, Kihara J, et al. (2011) Disease suppression by light-enhanced antioxidant system in broad bean. Curr Top Plant Biol 12: 55-61.

21. Ashry NA, Mohamed HI (2011) Impact of secondary metabolites and related enzymes in flax resistance and or susceptibility to powdery mildew. Afr $J$ Biotechnol 7: 78-85.

22. Hoagland DR, Arnon DI (1950) The water culture method for growing plants without soil. California Agricultural Experiment Station Circular, 347, University of California, Berkley, CA, USA.

23. Bates LE, Waldren RP, Teare ID (1973) Rapid determination of free proline for water stress studies. Plant Soil 39: 205-207.

24. Singleton VL, Orthofer R, Lamuela-Raventos RM (1999) Analysis of total phenols and other oxidation substrates and antioxidants by means of folinciocalteu reagent. Meth Enzymol 299: 152-178.

25. Obeley LW, Spitz DR (1984) Assay of superoxide dismutase activity in tumor tissue. Meth Enzymol 105: 457-467.

26. Kang JH (2004) Modification of $\mathrm{Cu}, \mathrm{Zn}$-superoxide dismutase by oxidized catecholamines. J Biochem Mol Biol 37: 325-329.

27. Beers RF, Sizer IW (1952) A spectrophotometric method for measuring the breakdown of hydrogen peroxide by catalase. J Biol Chem 195: 133-140.

28. Nakano Y, Asada K (1981) Hydrogen peroxide is scavenged by ascorbate specific peroxidase in spinach chloroplasts. Plant Cell Physiol 22: 867-880.

29. O'kane D, Gill V, Boyd P, Burdon RH (1996) Chilling, oxidative stress and antioxidant responses in Arabidopsis thaliana callus. Planta 198: 371-377.

30. Rajkumar M, Lee WH, Lee KJ (2005) Screening of bacterial antagonists for biological control of phytophthora blight of pepper. J Basic Microb 45: 55-63.

31. Phang JM, Liu W, Zabirnyk O (2010) Proline metabolism and microenvironmenta stress. Annu Rev Nutr 30: 441-463.

32. Luthria DL, Mukhopadhyay S, Krizek DT (2006) Content of total phenolics and phenolic acids in tomato (Lycopersicon esculentum Mill.) fruits as influenced by cultivar and solar UV radiation. J Food Compos Analysis 19: 771-777.

33. Johkan M, Shoji K, Goto F, Hashida S, Yoshihara T (2010) Blue light-emitting diode light irradiation of seedlings improves seedling quality and growth after transplanting in red leaf lettuce. Hort Sci 45: 1809-1814.

34. Schmidt M, Grief J, Feierabend J (2006) Mode of translational activation of the catalase (cat1) mRNA of rye leaves (Secale cereale L.) and its control through blue light and reactive oxygen. Planta 223: 835-846.

35. Xu Y, Sun X, Jin J, Zhou H (2010) Protective effect of nitric oxide on lightinduced oxidative damage in leaves of tall fescue. J Plant Physiol 167: 512-518.

36. Kuzniak E, Sklodowska M (2005) Fungal pathogen-induced changes in the antioxidant systems of leaf peroxisomes from infected tomato plants. Planta 222: 192-200.

37. Khanam NN, Ueno M, Kihara J, Honda YM, Arase S (2005) Suppression of red light-induced resistance in broad beans to Botrytis cinerea by salicylic acid. Physiol Mol Plant P 66: 20-29.

38. Grote D, Claussen W (2001) Severity of root rot on tomato plants caused by Phytophthora nicotianae under nutrient- and light-stress conditions. Plant Pathol 50: 702-707. 